\title{
ПРОТИРІЧЧЯ МЕТОДИКИ ОЦІНКИ СТАНУ ТА ПЕРІОДІВ ФОРМУВАННЯ СТІЙКОСТІ ФУНКЦІОНУВАННЯ ОРГАНІЗАЦІЙ
}

\section{CONTRADICTIONS OF THE CONDITION ASSESSMENT METHOD AND SUSTAINABILITY FORMATION PERIODS OF ORGANIZATIONS FUNCTIONING}

\author{
Гордєєва Інна Олександрівна \\ кандидат технічних наук, доцент, \\ експерт 3 акредитацій освітніх програм, \\ Національне агентство забезпечення якості вищої освіти \\ ORCID: https://orcid.org/0000-0002-2019-2527 \\ Hordieieva Inna \\ National Agency for Higher Education Quality Assurance
}

\begin{abstract}
Виконано постановку та розв'язання науково-прикладної задачі аналізу та виявлення протиріч методики оцінки стану та періодів фрормування стійкості фрункціонування організацій за Е.М. Коротковим. На основі графрічного аналізу виявлено три протиріччя. 1. Гомеостатичний рівень на графріку у випадку переломного періоду має вигляд точки, а трансформаційного періоду - пряму, що не може відображати період та характеризувати стан організації. 2. Невідповідність та недостатність деталізації розбивки площі показників між однорідними коефіцієнтами адаптації та синергії. 3. В граффічному представленні відсутні стабільний, квазістабільний, квазіперехідний стани та відповідно їх коефіцієнти адаптації та синергії. Надійність та точність результатів оцінки за даною методикою викликає сумнів. Визначені протиріччя потребують подальшого розв'язання.
\end{abstract}

Ключові слова: стійкість організації, антикризовий менеджмент, адаптація, синергія, перехідні процеси.

Выполнена постановка и решение научно-прикладной задачи анализа и выявления противоречий методики оценки состояния и периодов фрормирования устойчивости фуунционирования организаций по Э.М. Короткову. На основе графического анализа выявлено три противоречия. 1. гомеостатический уровень на графике в случае переломного периода имеет вид точки, а трансформационного периода - прямую, не может отражать период и характеризовать состояние организации. 2. Несоответствие и недостаточность детализации разбивки площади показателей между однородными коэффициентами адаптации и синергии. 3. В графическом представлении отсутствуют стабильное, квазистабильное, квазипереходное состояния и соответственно их коэффициенты адаптации и синергии. Надежность и точность результатов оценки по данной методике вызывает сомнение. Выявленные противоречия требуют дальнейшего решения.

Ключевые слова: устойчивость организации, антикризисный менеджмент, адаптация, синергия, переходные процессы.

The paper's purpose is to identify contradictions and prospects of the assessing method and stability formation periods of organizations for further research and improvement based on reviewing of the conditions use. To solve the tasks in the work were used the method of system approach, the method of analysis and synthesis, the method of structural analysis and design of systems, grouping, generalization. The formulation and solution of the scientific-applied problem of the analysis and revealing of contradictions of assessing method and stability formation periods of organizations function by E.M. Korotkov. The classification of the levels of transients and the mathematical model for calculating the coefficients of adaptation and synergy to determine the compliance of the level of transients in the organization are analyzed. The classification of the levels of transients and the mathematical model for calculating the coefficients of adaptation and synergy to determine the compliance of the level of transients in the organization are analyzed. Based on the graphical analysis, three contradictions were revealed. 1. The homeostatic level on the graph in the case of a turning point has the form of a point, and the transformation period - a line that can not reflect the period, characterize the state of the organization and give reliable results. It is proposed to introduce an interval that takes into account the deviation associated with various factors and the probabilistic nature of the assessment 
of socio-economic systems. 2. Inconsistency (coherence) of the model, which is associated with inconsistency and inadequacy of the breakdown of the area of indicators between homogeneous coefficients of adaptation and synergy. 3. In the graphical representation there are no "stable" (stable, quasi-stable) and "unstable" (quasi-transient) states and, accordingly, their coefficients of adaptation and synergy, and therefore half of the areas are not defined. The reliability and accuracy of the evaluation results by this method are questionable. The identified contradictions need further research and resolution, based on which the prospects for further research are formed. The developed approaches can be used to improve the procedure of crisis management and the formation of organizations' stability in any sector of the economy. The article may be of interest to senior managers and project managers.

Keywords: organization stability, crisis management, adaptation, synergy, transition processes.

Постановка проблеми. Глобальні економічні перетворення, спричинені пандемією COVID-19, Індустрією 4.0 та переходом до циркулярної економіки, які наразі відбуваються, як в світі, так і в Україні, роблять не актуальними для застосування ще вчора ефрективні методи антикризового управління. Ціллю розробки нових методів, моделей та механізмів $€$ забезпечення стійкості функціонування організацій, їх адаптацію до руйнівних сракторів глобальних економічних перетворень в період кризи. Наразі існує потреба в розробці та впровадженні дієвих методів, моделей та методологій управління в умовах турбулентності середовища VUCA задля забезпечення керованості соціально-економічними системами в різних галузях.

Аналіз останніх досліджень і публікацій. В роботі 3 антикризового менеджменту Е.М. Коротков [1, с. 107-110], описав класифікацію криз в розвитку організації, їх критерії та навів математичну модель визначення перехідного періоду. Методика набула універсального значення і використовується науковцями при оцінці адаптації порторельного управління [2-3], управління культурою в системі підприємництва [4], визначення кризового стану економічних систем [5], реструктуризації банківської сорери [6], управлінні інноваційною діяльністю на підприємствах [7], забезпеченні сталого розвитку машинобудівельних організацій [8], корпоративного контролю в процесі закупівель матеріально-технічних ресурсів [9, с. 76], формуванні стратегії сталого економічного розвитку газохімічних підприємств [10, с. 12] та інших.

Методика оцінки стану та періодів фрормування стійкості фрункціонування організацій отримала широке поширення та набула багатьох послідовників, які здійснюють її розвиток, покладена в основу багатьох кандидатських і докторських дисертацій, зустрічається практично у кожному другому навчальному посібнику 3 антикризового менеджменту і тому представляє інтерес широкого кола науковців.

Мета дослідження - здійснити огляд застосування методики оцінки стану та пері- одів фрормування стійкості фрункціонування організацій, виявити протиріччя та перспективи подальших досліджень.

Виклад основного матеріалу дослідження. Методика оцінки стану та періодів формування стійкості фрункціонування організацій Е.М. Короткова умовно включає дві частини: перша це опис трьох рівнів перехідних процесів (що за змістом $€$ класифрікацією перехідних процесів), а друга - математична модель розрахунку коефріцієнта адаптації та коесріцієнта синергії та основі них віднесення до одного 3 трьох рівнів перехідних процесів, описаних в першій частині. При цьому в багатьох наукових працях ці дві частини використовуються, як окремо одна від одної, так і разом.

Стан будь-якої організації умовно поділяють на стійкий та нестійкий. В свою чергу стійкий стан може бути або стабільним або квазістабільним. Нестійкий стан теж підрозділяється на два види - перехідний та квазіперехідний (рис. 1).

Перехідні періоди в системах класифікують за трьома рівнями: гомеостатичний, інноваційний та біфруркаційний [1, с. 107-110; 10, c. $12 ; 11$, с. 24-25; 12]. Перший гомеостатичний рівень підрозділяється на переломний та трансформаційний періоди. Другий (інноваційний) рівень на кризовий та комфортизаційний. Третій (біфуркаційний) рівень на катастрофрічний та кокірідний.

Для визначення стану організації в загальній структурі перехідних процесів в наукових джерелах [3; 11, с. 24-25] наводиться математична модель розрахунку коесріцієнту адаптації і коефріцієнту синергії, яка базується на визначенні швидкостей чотирьох процесів:

- процесу адаптації (А), який показує, як система пристосовується до змін, що відбуваються (И) в зовнішньому середовищі та у власному оточенні. Процес змін (И) ототожнюють 3 критерієм «керованість», що відображає ступінь підконтрольності та стабільності основних параметрів системи в перехідні періоди [12].

- процесу деструктуризації (Д), що показує, як система знижує свою складність. Зазвичай 


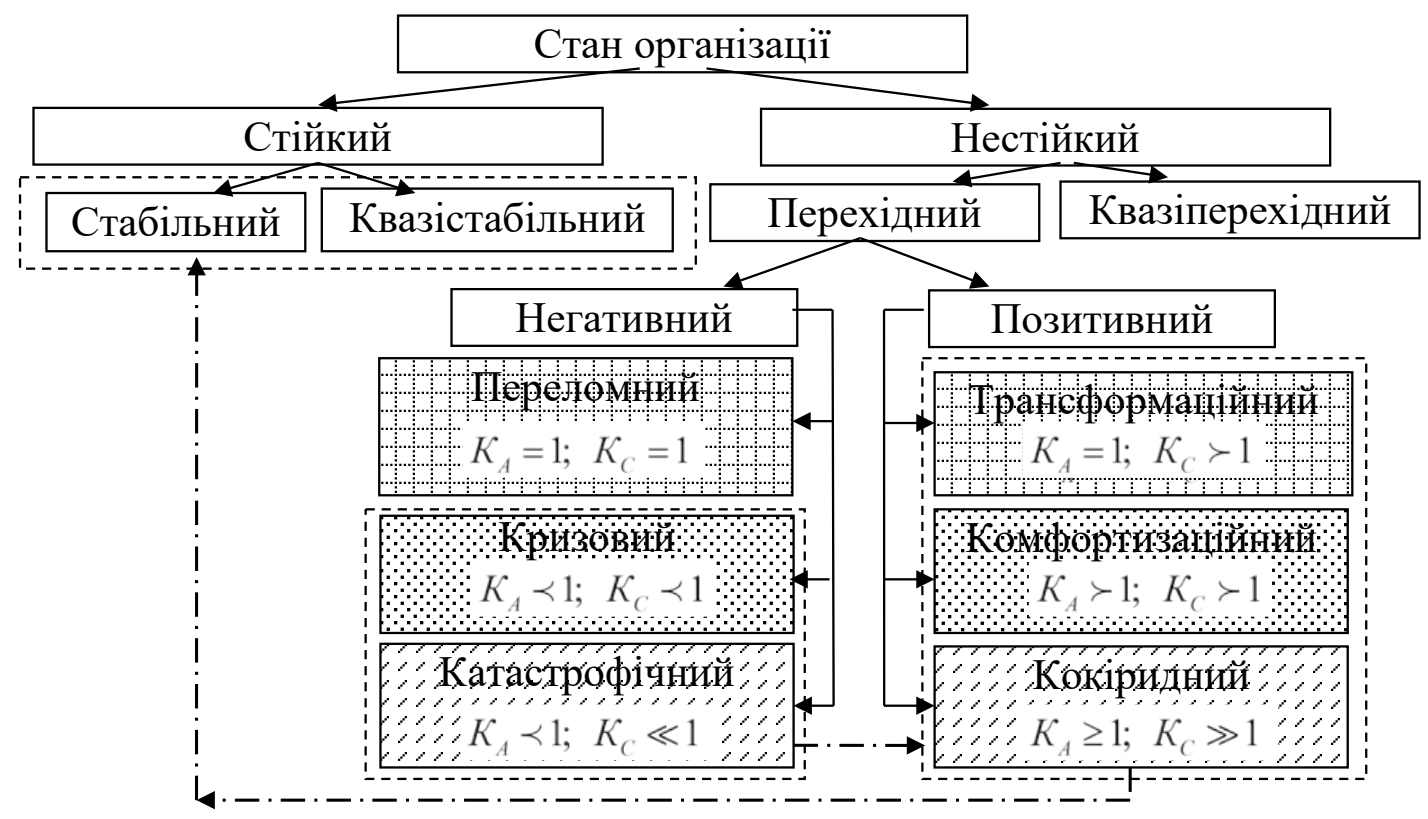

Рис. 1. Стан та етапи формування стійкості функціонування організацій в загальній структурі перехідних процесів

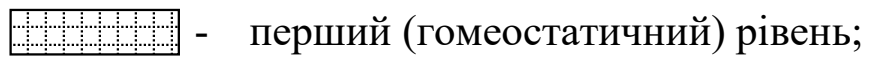

Зे - другий (інноваційний) рівень;

殿? - третій (біфуркаційний) рівень.

зміну складності в природничих науках вимірюють величиною ентропії [1, с. 107]. При чому ентропія показує рівень невизначеності змін стану системи в майбутньому при зниженні рівня ії складності (деструктурування бізнес-одиниць) [12].

- процесу синергоутворення (С), що відображає, як система збільшує свою складність [1, с. 107] та результативність при ефекттивній взаємодії її елементів [12].

Для розрахунку швидкостей процесів застосовуються фоормули (1-4):

$$
V_{A}=\frac{d A}{d t}, V_{n}=\frac{d h}{d t}, V_{D}=\frac{d Д}{d t}, V_{C}=\frac{d C}{d t},
$$

де $v_{A} ; V_{n} ; V_{д} ; V_{c}-$ швидкості відповідно процесів адаптації організації, змін у зовнішньому та внутрішньому середовищі, деструктуризації, синергоутворення; $d t$ - період часу за який фріксуються зміни.

Далі визначаються коесріцієнт адаптації $K_{A}$ та коесріцієнт синергії $K_{C}(5-6)$, які відображають відповідність між швидкостями.

$$
K_{A}=\frac{V_{A}}{V_{n}}=\frac{d A}{d U} ; K_{C}=\frac{V_{C}}{V_{D}}=\frac{d C}{d Д}
$$

Відношення до одного з цих рівнів (гомеостатичного, інноваційного або біфуркаційного) відбувається у відповідності до значення коефріцієнту адаптації $K_{A}$ та коефіцієнту синергії $K_{c}$ (табл. 1) [13].

Не зважаючи на велику кількість наукових робіт за описаною методикою, в них представлено тільки метод без наведених обчислень та результатів експерименту, що ускладнює використання на практиці.

Виключенням $€$ роботи [2-3], в яких коесріцієнт адаптації $K_{A}$ та коефріцієнт синергії $K_{C}$ розраховується через фрінансові показники, у тому числі проектної діяльності. Обсяг зароблених коштів дозволяє зробити висновки про те, як організація вела свою комерційну діяльність в попередньому короткотривалому періоді і не відображає темпи видозмін (адаптації) організації в теперішньому і майбутньому періодах. 3 оцінки прибутку складно зрозуміти в середньо- та довготривалому періодах кількість здійснених змін, їх якість, своєчасність, перспективність. Адаптація через реалізацію середньо- та довготривалих проектів відбувається 3 деякою інерцією у часі. Для прийняття управлінських рішень тут і зараз ця інфрормація застаріла і може призвести до прийняття помилкового рішення. 
Таблиця 1

Значення критеріальних коефіцієнтів для різних періодів розвитку організації

\begin{tabular}{|c|c|c|c|}
\hline Рівень & Період & $\boldsymbol{K}_{\boldsymbol{A}}$ & $\boldsymbol{K}_{\boldsymbol{C}}$ \\
\hline Гомеостатичний & Переломний & 1 & $>1$ \\
\hline & Трассрормаційний & 1 & $<1$ \\
\hline Інноваційний & Кризовий & $<1$ & $>1$ \\
\hline & Комфрортизаційний & $>1$ & $<<1$ \\
\hline Біфуркаційний & Катастрофічний & 1 & $>>1$ \\
\hline & Кокірідний & $\geq 1^{*}$ & \\
\hline
\end{tabular}

*В деяких джерелах кокірідним визначається період при якому $K_{A}=1$, а в інших $K_{C} \succ 1$. Обидва твердження можна вважати вірними, тому що процеси, що відбуваються при таких значеннях $€$ спорідненими, але потребують додаткових досліджень і перевірки.

Обсяг прибутку на перший погляд можна вважати достатньо чіткою величиною, але на практиці це не так. Грошові потоки можуть йти із запізненням або на час оцінки може здійснюватися проектна діяльність, яка використовує ресурси, але прибутків ще не приносить, хоча формує потенціал для подальшого зміцнення адаптаційних здатностей.

Проілюструємо наведену методику (табл. 1) в грасрічному вигляді. На основі аналізу отриманого грасрічного вигляду (рис. 2) можна виділити ряд протиріч та можливих шляхів їх вирішення.

Протиріччя 1. Перший гомеостатичний рівень, який підрозділяється на переломний та трансорормаційний періоди, представляє собою на графріку у випадку переломного періоду $\left(K_{A}=1, K_{C}=1\right)$ точку, а у випадку трансорормаційного періоду $\left(K_{A}=1, K_{C} \succ 1\right)-$ пряму. Організація в такому стані знаходиться не тривалий час і при відповідних значеннях коесріцієнтів можна говорити скоріш про окремий випадок такого стану, ніж період під яким розуміють відрізок часу, визначений мітками початку і кінця відліку.

Таким чином, реально існує імовірність похибки при розрахунку і частина розрахунків, відповідно до яких зазначені коефріцієнти відносять організацію до гомеостатичного рівня являються випадковим попаданням, що скоріш за все не відповідає дійсності. При значенні наближеному до 1, наприклад, $K_{A}=0,99$, $K_{c}=0,99$ перехідний період буде визначатися, як інноваційний кризовий рівень, а не гомеостатичний переломний.

Шляхи розв'язання протиріччя 1. Як зазначено в [14, с. 20] будь-яка організація відноситься до імовірнісних систем, тобто до таких, що не піддаються детальному опису.

Але розрахувати коефріцієнт адаптації $K_{A}$, коефріцієнт синергії $K_{C}$ та вихідні швидкості (відповідно процесів адаптації організації $V_{A}$, змін у зовнішньому та внутрішньому середовищі $V_{\text {и }}$, деструктуризації $V_{\text {д }}$, синергоутворення $V_{c}$ ) не можливо без застосування експертних оцінок. В свою чергу, експертні оцінки, як вже зазначалося вченими багато разів, мають суб'єктивність і можливі похибки, викликають спотворення підсумкової експертної думки.

На суб'єктивність може впливати багато фракторів, які не можливо виключити. Наприклад, абстрактність самих понять адаптації, змін в середовищі, диструктуризації, синергоутворення; вплив психосрізіологічних особливостей експерта, його зібраності, уважності.

Тобто в реальних умовах повністю виключити систематичну складову похибки неможливо. Завжди залишаються деякі чинники, які не були виключені, але які необхідно враховувати для того щоб оцінити їх границі. 3 цього і буде складатися систематична похибка вимірювання. Систематична похибка теж випадкова, а вказаний розподіл обумовлений лише прийнятими традиціями обробки та представлення результатів вимірювань.

Доцільно точність оцінки інтерпретувати у виді невизначеності вимірювання як ступеню довіри до отриманого результату, що $€$ основною ідеєю керівництва Guide to the Expression of Uncertainty in Measurement [15].

Але з попередніх зауважень зовсім не слідує, що гомеостатичного рівня не існує. Пропонується ввести деякий інтервал $\pm \Delta$, який врахує відхилення, що пов'язане з різними фракторами. Прийнято вважати, що якщо $\Delta_{0} \leq 0,25 \Delta$, то оцінка точності надійна [16, с. 51].

Якщо $P$ означає вірогідність $\alpha$ того, що $\bar{x}$ результату виміру відрізняється від істинного на величину не більш ніж $\Delta$, тобто (7):

$$
P=\alpha\left\{\bar{x}-\stackrel{\circ}{\Delta} x_{u} \prec \bar{x}+\stackrel{\circ}{ }\right\},
$$

то в цьому випадку $P$ - довірча вірогідність,

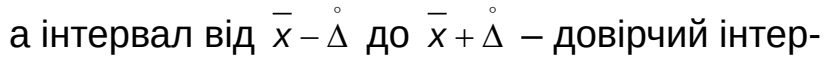




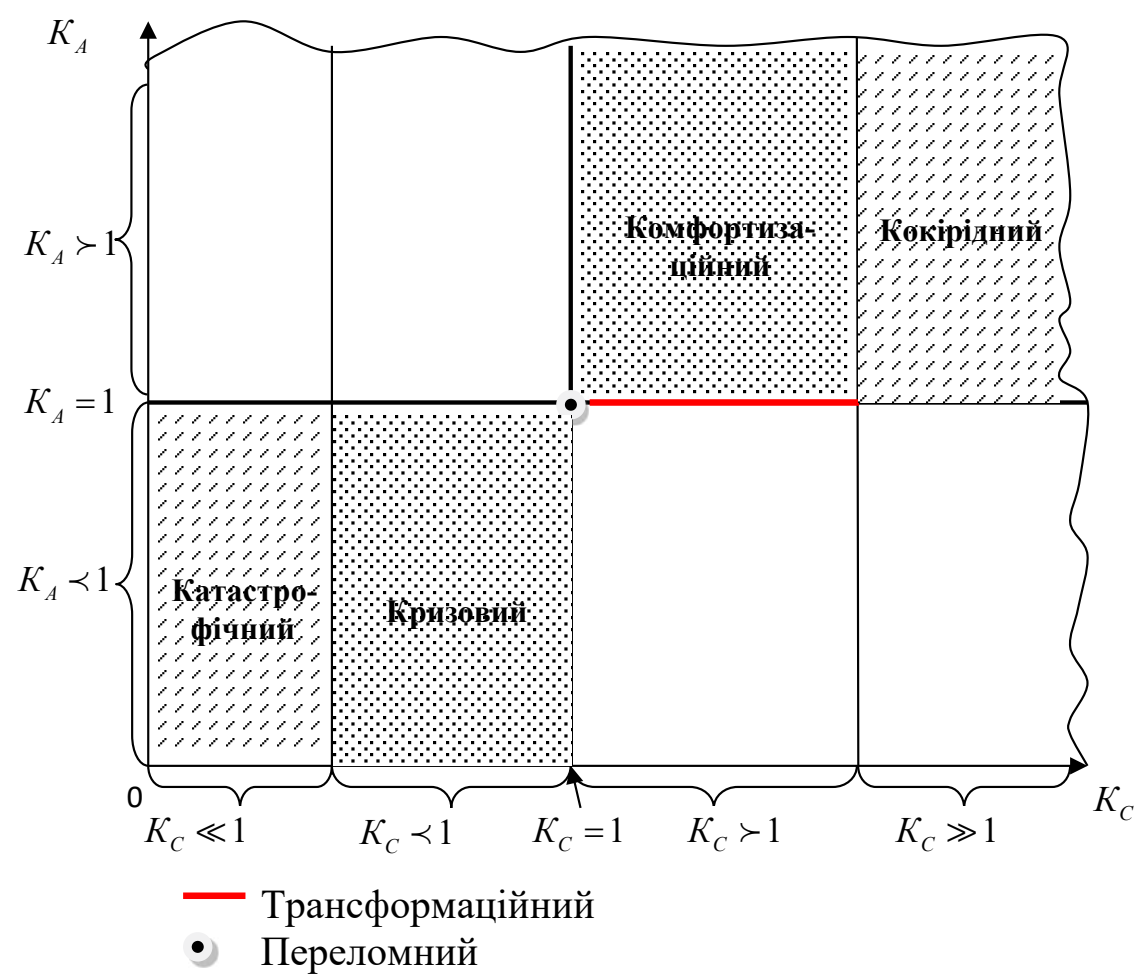

Рис. 2. Грасрічне представлення значень критеріальних коефіцієнтів для різних періодів розвитку організації

Джерело: розроблено автором

вал. Отже, для характеристики випадкової похибки необхідно обов'язково задати два числа - величину самої похибки (або довірчий інтервал) та довірчу вірогідність.

Протиріччя 2. Стан та етапи формування стійкості фрункціонування організацій визначаються відповідно до коесріцієнту $K_{A}$ тільки в границях $[\succ 1 ; \infty]$ або $[\prec 1 ; 0]$ на відміну від коефріцієнту $K_{C}$, який розбиває площу показників

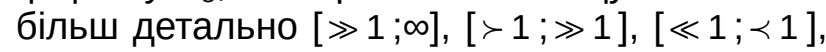
[«1;0] (рис. 2).

Таке деталізоване представлення $€$ доречним, тому що зрозуміло, що, наприклад, при значеннях в одному випадку, коли $K_{A}=1,5$, $K_{C}=1,5$ та значеннях $K_{A}=105, K_{C}=1,5$ в іншому випадку, перехідні процеси в організації будуть суттєво відрізнятися.

Отже, можна виділити протиріччя в деталізації розбивки площі показників між однорідними коефіцієнтами адаптації та синергії, що свідчить про неузгодженість (когерентність) моделі.

Шляхи розв'язання протиріччя 2. Тому пропонується збільшити кількість інтервалів оцінювання показника КА шляхом нанесення $[\gg 1 ; \infty],[\succ 1 ; \gg 1],[\ll 1 ; \prec 1],[\ll 1 ; 0]$. Однак потребують уточнення граничні значення при яких, як коефріцієнт адаптації $K_{A}$, так і коефрі- цієнт синергії $K_{c}$ будуть вважатися такими, що відповідають значенню »1 та «1. Це питання потребує подальшого дослідження та уточнення.

Протиріччя 3. На грасріку відсутні «стійкий» (стабільний, квазістабільний) та «нестійкий» (квазіперехідний) стани та відповідно їх коефріцієнти адаптації $K_{A}$ та синергії $K_{C}$ (див. рис. 1 та 2), а отже половина областей не визначена. В подальшому необхідно уточнити термінологію цих понять для єдиного розуміння та виключення багатозначності. Це протиріччя потребує подальшого дослідження та розв'язання.

Висновки та перспективи дослідження. Проаналізовано методику оцінки стану та періодів фрормування стійкості фуннкціонування організацій Е.М. Короткова, а саме класифрікація рівнів перехідних процесів та математична модель розрахунку коефіцієнтів адаптації та синергії задля визначення відповідності рівню перехідного процесу в організації.

На основі графрічного аналізу виявлено три протиріччя:

1. Перший гомеостатичний рівень, представляє собою на грасріку у випадку переломного періоду точку, а у випадку трансформаційного періоду - пряму, що не може 
відображати період, характеризувати стан організації та давати надійні результати.

2. Невідповідна та недостатня деталізація розбивки площі показників між однорідними коефріцієнтами адаптації та синергії, що свідчить про неузгодженість (когерентність) моделі.

3. В графрічному представленні відсутні «стійкий» (стабільний, квазістабільний) та «нестійкий» (квазіперехідний) стани та відповідно їх коесріцієнти адаптації та синергії, а отже половина областей не визначена.

Таким чином, можна поставити під сумнів надійність та точність результатів оцінки за даною методикою. Визначені протиріччя потребують подальшого дослідження та розв'язання.

\section{СПИСОК ВИКОРИСТАНИХ ДЖЕРЕЛ:}

1. Коротков Э.М. Антикризисное управление : учеб. пособие. Москва : ИНФРА-М, 2003. С. 432.

2. Молоканова В.М. Аналіз синергетичних аспектів адаптації організації до змін зовнішнього середовища через портсель проектів. Восточно-Европейский журнал передовых технологий. 2015. № 5(3). С. 4-10.

3. Molokanova V. M., Hordieieva I. O. Study of the organization adaptivity rate correlation in relation to its internal integrity. Scientific journal herald of advanced information technology. 2020. Vol. 3. № 4. Pp. 292-304. doi: 10.15276/ hait.04.2020.7

4. Левкин Н.В. Современные тенденции управления культурой в системе предпринимательства. Петрозаводск : ПетрГУ, 2009. С. 342.

5. Букреев А.М., Дударев О.Е., Зубкова Н.В. Системологический подход к управлению организацией в кризисных условиях. Организатор производства. 2007. № 1. С. 30-33.

6. Дзюбан С.В. Антикризисное управление коммерческими банками в условиях реструктуризации банковской системы : дис. ... канд. экон. наук : 08.00.10. Оренбург, 2003. 192 с.

7. Погорелова Л.А. Формирование непрерывных инновационных процессов на предприятиях в условиях становления цифровой экономики : дис. ... канд. экон. наук : 08.00.05. Москва, 2019. 176 с.

8. Туников В.А. Организационно-экономическое обеспечение устойчивого развития машиностроительного предприятия : дис. ... канд. экон. наук : 08.00.05. Новочеркасск, 2002. 230 с.

9. Хальфин Р.М. Механизмы и методы корпоративного контроля в процессе закупок материально-технических ресурсов : дис. ... канд. экон. наук : 08.00.05. Москва, 2018. 159 с.

10. Соловьев Ю.Ю. Формирование стратегии устойчивого экономического развития газохимических предприятий : авторефр. дис. ... канд. экон. наук : 08.00.05. Астрахань, 2007. 24 с.

11. Патласов О.Ю., Сергиенко О.В. Антикризисное управление. Финансовое моделирование и диагностика банкротства коммерческой организации. Москва : Книжный мир, 2009. С. 512.

12.Джуха В.М., Сааков А.С. Системная стабилизация в антикризисном управлении как средство предотвращения банкротства. Управление экономическими системами: электронный научный журнал. 2014. № 12(72). URL: http://uecs.ru/uecs-72-722014/item/3233-2014-12-16-08-03-55

13. Лунев В.Л. Тактика и стратегия управления фирмой : учебное пособие. Москва : Финпресс, 1997. С. 356.

14. Малышенко А.М. Математические основы теории систем : учеб. для вузов. Томск : Томский политехнический университет, 2008. С. 364.

15. Evaluation of measurement data - Guide to the expression of uncertainty in measurement JCGM 100: 2008 GUM 1995 with minor corrections, 2008. 134 p.

16. Сергеев А.Г., Латышев М.В., Терегеря В.В. Метрология, стандартизация, сертисикация : учеб. пособие. Москва : Логос, 2003. С. 536.

\section{REFERENCES:}

1. Korotkov E.M. (2003). Antikrizisnoe upravlenie: ucheb. posobie [Crisis Management: A Study Guide]. Moscow: INFRA-M. (in Russian)

2. Molokanova V.M. (2015). Analiz synerhetychnykh aspektiv adaptatsii orhanizatsii do zmin zovnishnoho seredovyshcha cherez portfel proektiv [Analysis of synergetic aspects of the organization's adaptation to changes in the external environment through a portfolio of projects]. Vostochno-Evropeyskiy zhurnal peredovyih tehnologiy Eastern European Journal of Advanced Technologies, 5(3), 4-10. (in Ukrainian)

3. Molokanova V.M., Hordieieva I.O. (2020). Study of the organization adaptivity rate correlation in relation to its internal integrity. Scientific journal herald of advanced information technology, 3(4), 292-304. doi: 10.15276/hait.04.2020.7

4. Levkin N.V. (2009). Sovremennyie tendentsii upravleniya kulturoy v sisteme predprinimatelstva [Modern trends in culture management in the system of entrepreneurship]. Petrozavodsk: PetrGU. (in Russian) 
5. Bukreev A.M., Dudarev O.E., Zubkova N.V. (2007). Sistemologicheskiy podhod k upravleniyu organizatsiey v krizisnyih usloviyah [Systemological approach to managing an organization in crisis conditions]. Organizator proizvodstva - Production organizer, 1, 30-33. (in Russian)

6. Dzyuban S.V. (2003). Antikrizisnoe upravlenie kommercheskimi bankami v usloviyah restrukturizatsii bankovskoy sistemyi [Anti-crisis management of commercial banks in the context of banking system restructuring]. Candidate's thesis. Orenburg. (in Russian)

7. Pogorelova L.A. (2019). Formirovanie nepreryivnyih innovatsionnyih protsessov na predpriyatiyah v usloviyah stanovleniya tsifrovoy ekonomiki [Formation of continuous innovation processes at enterprises in the context of the formation of the digital economy]. Candidate's thesis. Moscow. (in Russian)

8. Tunikov V.A. (2002). Organizatsionno-ekonomicheskoe obespechenie ustoychivogo razvitiya mashinostroitelnogo predpriyatiya [Organizational and economic support for the sustainable development of a machine-building enterprise]. Candidate's thesis. Novocherkassk. (in Russian)

9. Halfin R.M. (2018). Mehanizmyi i metodyi korporativnogo kontrolya v protsesse zakupok materialno-tehnicheskih resursov [Mechanisms and methods of corporate control in the procurement of material and technical resources]. Candidate's thesis. Moscow. (in Russian)

10. Solovev Yu.Yu. (2007) Formirovanie strategii ustoychivogo ekonomicheskogo razvitiya gazohimicheskih predpriyatiy [Formation of a strategy for sustainable economic development of gas chemical enterprises]. Extended abstract of Candidate's thesis. Astrahan. (in Russian)

11. Patlasov O.Yu., Sergienko O.V. (2009). Antikrizisnoe upravlenie. Finansovoe modelirovanie i diagnostika bankrotstva kommercheskoy organizatsii [Crisis management. Financial modeling and diagnostics of the bankruptcy of a commercial organization]. Moscow: Knizhnyiy mir. (in Russian)

12. Dzhuha V.M., Saakov A.S. (2014). Sistemnaya stabilizatsiya v antikrizisnom upravlenii kak sredstvo predotvrascheniya bankrotstva [Systemic stabilization in anti-crisis management as a means of preventing bankruptcy]. Upravlenie ekonomicheskimi sistemami - Economic systems management, 12(72). (in Russian)

13. Lunev V.L. (1997). Taktika i strategiya upravleniya firmoy: uchebnoe posobie [Firm management tactics and strategy: a tutorial]. Moscow: Finpress. (in Russian)

14. Malyishenko A.M. (2008). Matematicheskie osnovyi teorii sistem: uchebnik dlya vuzov [Mathematical foundations of systems theory: a textbook for universities]. Tomsk: Tomskiy politehnicheskiy universitet. (in Russian)

15. Evaluation of measurement data - Guide to the expression of uncertainty in measurement JCGM 100: 2008 GUM 1995 with minor corrections, 2008. 134 p.

16. Sergeyev A.G., Latyshev M.V., Teregerya V.V. (2003). Metrologiya, standartizatsiya, sertifikatsiya: uchebnoe posobie [Metrology, standardization, certification: textbook]. Moscow: Logos. (in Russian) 